\title{
Tomografia computadorizada da matriz óssea mineralizada heteróloga fragmentada e metilmetacrilato na reparação de falhas ósseas segmentares produzidas em tíbia de coelhos
}

\author{
[Computed tomography to evaluate the association of fragmented heterolog cortical bone \\ and methylmethacrylate to repare segmental bone \\ defect produced in tibia of rabbits] \\ S.H. Freitas ${ }^{1,3}$, R.G.S. Dória ${ }^{2}$, F.S. Mendonça ${ }^{3}$, M.D. Santos ${ }^{3}$, R. Moreira ${ }^{4}$, \\ R.S. Simões ${ }^{5}$, L.M. Camargo ${ }^{1,6}$, A.T.C. Marques ${ }^{7}$, M.J. Simões ${ }^{6}$ \\ ${ }^{1}$ Pós-doutorando - Universidade Federal de São Paulo, SP \\ ${ }^{2}$ Faculdade de Zootecnia e Engenharia de Alimentos - Universidade de São Paulo, SP \\ ${ }^{3}$ Faculdade de Medicina Veterinária - Universidade de Cuiabá, MT \\ ${ }^{4}$ Aluno de pós-graduação - Faculdade de Medicina Veterinária - Universidade de Cuiabá, MT \\ ${ }^{5}$ Médico do Hospital Universitário - Universidade de São Paulo, SP \\ ${ }^{6}$ Escola Paulista de Medicina - Universidade Federal de São Paulo, SP \\ ${ }^{7}$ Faculdade de Odontologia - Universidade de Cuiabá - Cuiabá, MT
}

\begin{abstract}
RESUMO
Foi realizada falha segmentar de $6 \mathrm{~mm}$ na região metafisária medial da tíbia de 12 coelhos, seguida de preenchimento desta por matriz óssea mineralizada heteróloga fragmentada conservada em glicerina (98\%) e metilmetacrilato autoclavado, bem como avaliação por meio da tomografia computadorizada de feixe cônico (cone beam) aos 30, 60 e 90 dias. Houve incorporação gradativa do implante no leito receptor em relação ao tempo em $100 \%$ dos casos, o que mostra ser este biologicamente compatível, ao promover reparação da falha óssea, sem sinais de infecção, migração e/ou rejeição, caracterizando-se, assim, como nova opção de substituto ósseo para preenchimento de falhas ósseas.
\end{abstract}

Palavras-chave: coelho, implante ósseo, substituto ósseo, tomografia computadorizada, ortopedia

\begin{abstract}
A $6 \mathrm{~mm}$ segmental defect was performed on the metaphyseal region of the tibia of 12 rabbits and the autoclaved fragmented heterolog cortical bone conserved in glycerin (98\%) and methylmethacrylate was used as a bone graft for the reconstruction. The graft was placed in the receptor bed and its integration was evaluated by computed tomography after 30,60 and 90 days. There was gradual bone graft incorporation in the receptor bed during the time in 100\% of the cases. Fragmented cortical bone heterograft and methylmethacrylate was biologically compatible and promotes bone defect reparation without signs of infection, migration and or rejection, featuring a new option of osseous substitute to fill in bone defects.
\end{abstract}

Keywords: rabbit, bone graft, osseous substitute, computed tomography, orthopedics

\section{INTRODUÇÃO}

As fraturas com perda de quantidade substancial de tecido ósseo têm papel de destaque na rotina clínico-cirúrgica, tanto na medicina veterinária quanto na medicina humana, não sendo rara também a presença de outras afecções concomitantes, como as neoplasias ósseas e/ou

Recebido em 24 de julho de 2011

Aceito em 10 de maio de 2012

E-mail:shfreitas@terra.com.br não uniões que necessitam de procedimentos ortopédicos reparadores envolvendo a reposição óssea (Ranzani et al., 1996; Rezende et al., 1998; Alievi et al., 2007). A melhor opção para tratar as falhas ósseas é o enxerto autólogo, ou seja, fragmentos ósseos colhidos do próprio paciente, uma vez que é biologicamente compatível e acelera a reparação óssea. No entanto, esta técnica possui o inconveniente de aumentar a 
morbidade, a dor, o tempo anestésico e cirúrgico e de lesar estruturas normais, além de não fornecer volume suficiente para reparar grandes falhas ósseas (Melo et al., 1998; Alievi et al., 2007).

Os biomateriais são definidos como qualquer material não vivo de origem biológica ou sintética, utilizados na área médica, que interaja com o sistema vivo e que seja biocompatível (Turrer e Ferreira, 2008; Raposo-do-Amaral, 2010). Os tecidos ósseos obtidos de animais da mesma espécie, ou seja, os aloimplantes, ou de espécies diferentes, os heteroimplantes, são biomateriais biológicos que têm sido utilizados com resultados satisfatórios na reparação de falhas ósseas (Melo et al., 1998; Silva et al., 2003; Morais et al., 2004; Alievi et al., 2007; Freitas et al., 2008).

Os heteroimplantes devem promover a osteoindução, que se dá pela formação de osso a partir de células osteoprogenitoras, oriundas das células mesenquimatosas primitivas, sob a influência de um ou mais agentes indutores da matriz óssea, e a osteocondução que se caracteriza pelo crescimento ósseo por meio de aposição de tecido ósseo subjacente na presença de osso ou células mesenquimatosas indiferenciadas. Eles devem ser biocompatíveis, não carcinogênicos, atóxicos, não antigênicos e não devem estimular processos inflamatórios nem favorecer a infecção (Alexander, 1987; Akamoto e Trento, 2002).

Um banco de ossos torna os procedimentos reparadores mais eficientes, devido à constante disponibilidade de tecidos, podendo atender a mais de um paciente ao mesmo tempo (Iamaguti et al., 1995; Alievi et al., 2007; Freitas et al., 2008). Para serem estocados, os tecidos ósseos devem ser coletados assepticamente, acondicionados e preservados em meios adequados, para que não se degenerem e para que suas propriedades osteoindutoras e/ou osteocondutoras sejam mantidas. Os métodos de preservação mais utilizados em banco de ossos são o congelamento com nitrogênio, resfriamento, liofilização, autoclavagem, óxido de etileno, álcool $70 \%$, glicerina $98 \%$, entre outros (Melo et al., 1998; Freitas et al., 2001; Silva et al., 2003; Vilela et al., 2010).
As falhas ósseas também podem ser eficientemente preenchidas por biomateriais sintéticos, como cimento de fosfato de cálcio, hidroxiapatita, copolímero lacticoglicólico, metilmetacrilato, entre outros (Weinfeld et al., 1999; Yacubian-Fernandes et al., 2004; Alves et al., 2010; De Marval et al., 2011; Spadeto Jr. et al., 2011). Atualmente, o metilmetacrilato está sendo amplamente utilizado no reparo de grandes falhas ósseas, por apresentar propriedades bioinertes, com possibilidades de ser trabalhado e/ou moldado para obtenção de uma forma mais adequada ao leito receptor (Bauer e Muschler, 2000; Yacubian-Fernandes et al., 2004; Raposodo-Amaral et al., 2010).

Uma nova opção para reparar falhas ósseas extensas seria a utilização, de forma associada, de um composto (implante) constituído por biomateriais biológicos (ossos) e sintéticos (metilmetacrilato), que apresentasse propriedades osteogênicas, osteoindutoras e osteocondutoras, que não favorecesse a infecção nem a colonização bacteriana, que proporcionasse sustentação mecânica, sendo de fácil aquisição, baixo custo, que não necessitasse de meio especializado para sua preservação e que preenchesse completamente a falha óssea, eliminando, com isso, os problemas inerentes ao enxerto autógeno (Melo et al., 1998; Alievi et al., 2007; Turrer e Ferreira, 2008).

Para se avaliar o comportamento dos implantes em falhas ósseas, a tomografia computadorizada (TC) constitui uma das técnicas de escolha, visto que permite visualizar tridimensionalmente todas as estruturas em camadas, principalmente de tecidos mineralizados. A TC é um método de diagnóstico por imagem que emprega a radiaçãox, obtendo a reprodução de uma secção de cortes de tecidos em qualquer um dos três planos espaciais. Diferindo da técnica radiográfica convencional, que projeta em um único plano todas as estruturas penetradas pela radiação- $\mathrm{x}$, a TC evidencia as relações estruturais em profundidade, mostrando imagens em cortes seriados (fatias) dos tecidos, com uma definição precisa, permitindo, dessa forma, avaliar, delimitar e quantificar as reações e/ou irregularidades nos tecidos, em especial o tecido ósseo (Murilo et al., 1999; Garib et al., 2007; Silveira e Wassall, 2009). 
Propõe-se, com este estudo, avaliar o comportamento da matriz óssea mineralizada heteróloga fragmentada (MOMHF) associada ao metilmetacrilato no preenchimento de falhas ósseas segmentares produzidas em tíbia de coelhos em diferentes tempos, por meio de tomografia computadorizada de feixe cônico (cone beam).

\section{MATERIAL E MÉTODOS}

Para confecção do implante a ser utilizado neste estudo, a MOMHF foi coletada assepticamente a partir de diáfise de tíbia de cães, clinicamente hígidos, que vieram a óbito por trauma. Para tanto, foram removidos tecidos moles adjacentes à tíbia, as epífises e a medula óssea, sendo a diáfise lavada com solução salina $0,9 \%$ (Solução salina - JP Indústria Farmacêutica S/A, Ribeirão Preto, SP) e acondicionada em glicerina a $98 \%$ (Glicerina - VIC Pharma Indústria e Comércio Ltda., Taquatitinga,SP) em recipiente de vidro esterilizado, por um período não inferior a 30 dias, em temperatura ambiente. Após esse período, a diáfise da tíbia conservada em glicerina a $98 \%$ foi hidratada com solução salina $0,9 \%$ por 10 minutos e, em seguida, fragmentada em partículas de aproximadamente $2 \mathrm{~mm}$, utilizando-se de cisalha ortopédica e, posteriormente, foi desidratada em temperatura ambiente. Em seguida, estes fragmentos (MOMHF) foram misturados, na mesma proporção, à resina acrílica de metilmetacrilato (Papel crepado - Esterilife Medical Ltda., Belo Horizonte, MG), moldados em uma forma de $6 \mathrm{~mm}$ de diâmetro por $2 \mathrm{~mm}$ de espessura, originando, dessa forma, o implante (associação de MOMHF e metilmetacrilato), o qual foi embalado em papel crepado (Vipi Flash - Vipi Indústria, Comércio, Exportação e Importação, Pirassununga, SP) e esterilizado em autoclave.

Como receptores do implante, foram utilizados 12 coelhos adultos, da raça Nova Zelândia, pesando em média $3 \mathrm{~kg}$, distribuídos em três grupos de quatro animais: E1 (30 dias), E2 (60 dias) e E3 (90 dias). No período pré-operatório, os animais foram mantidos em jejum hídrico e alimentar por duas horas e foi realizada a tricotomia da região proximal medial das tíbias direitas. O protocolo anestésico foi constituído da associação de acepromazina (Acepran 0,2\% Univet S/A, São Paulo, SP) $(0,1 \mathrm{mg} / \mathrm{kg})$ e tiletamina/zolazepam (Zoletil 50 - Virbac do
Brasil Indústria e Comércio Ltda., São Paulo, SP) $(20 \mathrm{mg} / \mathrm{kg})$, via intramuscular, seguido de bloqueio anestésico local infiltrativo com lidocaína 2,0\% (Lidovet - Bravet, Rio de Janeiro, RJ) $(0,4 \mathrm{~mL})$ no local da incisão.

Os animais foram posicionados em decúbito dorsal e a antissepsia foi realizada com povidona iodo (Riodeine tópico - Indústria Farmacêutica Rioquímica Ltda., São Paulo, SP). Na sequência, promoveu-se uma incisão sobre a pele, divulsão do subcutâneo, incisão sobre o periósteo e exposição do córtex proximal e medial da tíbia direita. Neste momento, realizou-se uma falha óssea na tíbia dos animais, pela remoção de um segmento cortical, de seis milímetros de diâmetro, utilizando-se de uma broca trefina (Broca trefina - Dental Aragão, São Paulo, SP), acoplada a uma furadeira elétrica autoclavável (Furadeira elétrica autoclavável - Caomédica, SP).

O defeito ósseo previamente criado foi preenchido com o implante anteriormente confeccionado, o periósteo e o subcutâneo foram aproximados com fio categute cromado 3.0 (Categut - Ethicon/Johnson \& Johnson Company, São José dos Campos, SP), utilizandose padrão de sutura contínua, e a pele foi suturada com fio poliamida 3.0 (Nylon Brasmédica, São Paulo, SP). Cada animal recebeu cinco aplicações, a cada 24h, de enrofloxacina (Flotril 2,5\% - Intervet - ScheringPlough, Rio de Janeiro, RJ $)^{13}(10 \mathrm{mg} / \mathrm{kg})$, via subcutânea, três aplicações, a cada $24 \mathrm{~h}$, de flunixin meglumine (Banamine pet - Intervet Schering-Plough, Rio de Janeiro, RJ) $(1,1 \mathrm{mg} / \mathrm{kg})$ e dois curativos diários com rifamicina (Rifocina - Sanofi-Aventis, São Paulo, SP) sobre a ferida, até a retirada dos pontos, que ocorreu no $10^{\circ}$ dia. No período pós-operatório, os animais foram alojados individualmente em gaiolas, alimentados com ração comercial (Ração Labina - Purina, São Paulo, SP) e água ad libitum.

As falhas ósseas implantadas e as áreas adjacentes foram avaliadas com o uso de um tomógrafo computadorizado volumétrico de feixe cônico - cone beam (modelo Kodak 9000 3D, Carestream Health - França), no pósoperatório imediato e aos 30, 60 e 90 dias consecutivos. 
Esta pesquisa foi aprovada pelo Comitê de Ética em Pesquisa da Universidade Federal de São Paulo/Hospital São Paulo, sob o número 0664/10, de 28 de maio de 2010, de acordo com a resolução 196/96 do Conselho Nacional de Saúde.

\section{RESULTADOS E DISCUSSÃO}

A coleta de tecido ósseo cortical canino e a sua preservação em glicerina a $98 \%$ é um procedimento simples e exequível (Silva et al., 2003), como demonstrado neste estudo, o que estimula a implantação de banco de ossos em centros cirúrgicos, em especial os veterinários. Para o preparo do implante, todos os materiais, instrumentos e luvas, utilizados para manipular a MOMHF e o metilmetacrilato, foram esterilizados. Além desses cuidados, antes do uso, o implante foi submetido ao processo de esterilização por meio de autoclave, que, para Vilela et al. (2010), é fundamental para o sucesso da cirurgia, já que previne a infecção local, evitando, dessa forma, a lise óssea, o que facilitaria a migração do implante do leito receptor.

Embora a literatura não estabeleça tempo mínimo e máximo de permanência do tecido ósseo em glicerina a 98\%, a MOMHF utilizada na confecção do implante foi mantida por um período não inferior a 30 dias, ocasião em que foi utilizada (Melo et al., 1998; Freitas et al., 2008; Vilela et al., 2010). Mesmo conhecendo as propriedades conservadoras e bactericidas da glicerina a 98\%, para uso, a MOMHF, após ser incorporada ao metilmetacrilato, foi submetida ao processo de esterilização com o uso de autoclave, garantindo, assim, a ausência completa de patógenos no implante, primando pela excelência da técnica.

A diáfise proximal medial da tíbia de coelhos foi eleita para ser o leito receptor, por ser de fácil acesso e, também, por possuir pouco tecido mole adjacente, tornando o procedimento cirúrgico rápido (Piermattei e Greeley, 1988; Rezende et al., 1998). Além disso, essa região também é sede de reabsorção e de propriedades osteogênicas da medula óssea, sendo, inclusive, metabolicamente, a mais ativa desse osso. Essas características são desejáveis e contribuem para uma resposta fisiológica mais rápida e eficiente entre o compósito em estudo e o leito receptor
(Suominen et al., 1995; Rezende et al., 1998; Turrer e Ferreira., 2008).

No período pós-operatório imediato, todos os animais apoiaram o membro operado, demonstrando que o suporte da tíbia não foi comprometido e que a analgesia empregada foi eficiente (Melo et al., 1998). Onze animais $(91,7 \%)$ tiveram as feridas cicatrizadas em 10 dias, sem sinais de infecção ou reação tecidual, mostrando que a antissepsia e assepsia, a antibioticoterapia e o tratamento das feridas foram adequados. Além disso, o meio de conservação do tecido ósseo, bem como o método de esterilização empregado, mostrou-se apropriado, não sendo observada alteração local que caracterizasse rejeição do compósito ao leito receptor (Iamaguti et al., 1995; Garib et al., 2007). Apenas um animal apresentou deiscência de pontos de pele $(8,4 \%)$ por automutilação, sem exposição do tecido subcutâneo, a qual foi tratada com rifamicina até a cicatrização, que se deu no $12^{\circ}$ dia pós-operatório.

Outra complicação da utilização de MOMHF associada ao metilmetacrilato como implante seria a necrose térmica óssea promovida pela alta temperatura atingida na polimerização do metilmetacrilato durante o preparo do implante. De acordo com Turrer e Ferreira (2008), esta reação exotérmica promoveria lise óssea e, consequentemente, facilitaria o deslocamento do implante a partir do leito receptor na tíbia. Neste ínterim, o implante foi previamente moldado em um gabarito e, somente então, encaixado na falha óssea, excluindo a elevada temperatura como fator complicador da técnica. Dessa forma, pode ser observado, neste estudo, ausência de reações entre o implante e o leito receptor, como, por exemplo, proliferações, lise óssea e/ou infecção. Provavelmente estes resultados estão associados ao emprego correto da técnica cirúrgica e, também, ao uso adequado de métodos de esterilização, que, para Dipisa et al. (1976) e Yacubian-Fernandes et al. (2004), são fatores decisivos para que haja integração dos implantes.

Além disso, resultados promissores na associação da MOMHF ao metimetacrilato na reparação de falhas ósseas podem ser esperados, já que, em todos os animais estudados, ocorreu a permanência do implante no leito receptor. Segundo Silva et al. (2003) e Turrer e Ferreira (2008), este fato é indicativo de ausência de 
rejeição e da presença de osteointegração, caracterizada pela neoformação vascular e pela invasão tissular de fibroblastos com deposição gradativa de novo osso, o que caracteriza, também, a osteocondução.

O emprego da tomografia computadorizada neste estudo permitiu acompanhar e demonstrar satisfatoriamente o comportamento dos implantes nas tíbias dos coelhos (grupos E1, E2 e E3). Na odontologia humana, avaliações tomográficas de feixe cônico são amplamente empregadas para avaliar tecido ósseo mineralizado e acompanhar remodelações ósseas, já que esta técnica permite a reprodução de imagens tridimensionais dos tecidos com mínima distorção (Garib et al., 2007; Silveira e Wassal, 2009).

Sendo assim, neste estudo, as avaliações tomográficas no pós-operatório imediato mostraram que todos os implantes permaneceram posicionados no leito receptor (Fig. 1).

As avaliações tomográficas dos cortes coronal e axial, realizadas nas tíbias dos coelhos dos grupos E1 (Fig. 2), E2 (Fig. 3) e E3 (Fig. 4), localizaram todos os implantes no interior dos leitos receptores, sem sinal de proliferação e/ou lise óssea nem reações que caracterizassem infecção e/ou rejeição. Como pode ser observado, os implantes preencheram as falhas ósseas, porém ainda não se tem conhecimento se as células ósseas ativas irão conseguir adentrar os poros do metilmetacrilato e depositar matriz óssea no implante (Turrer e Ferreira, 2008).
Foi possível verificar densidades heterogêneas nas tomografias computadorizadas de todos os implantes, compostas por áreas radioluscentes, correspondentes ao metilmetacrilato, e áreas radiopacas, referentes à MOMHF, desde o dia da implantação até os 90 dias de avaliação (Fig. 2B, 3B e 4B).

Pesquisas que utilizaram biomateriais biológicos, realizadas por Weinfeld et al. (1999), Gutierres et al. (2006) e Freitas et al. (2008), mostraram que o heteroimplante ósseo cortical (MOMHF) conservado em glicerina a $98 \%$ promove reparação em falha óssea. Yacubian-Fernandes $e t$ al. (2004) e Raposo-do-Amaral et al. (2010) divulgaram que os biomateriais sintéticos, como o metilmetacrilato, também podem ser empregados na correção de defeitos ósseos. Para Turrer e Ferreira (2008), a associação de dois ou mais materiais de classes diferentes, denominados compósitos, confere uma melhor performance, pois podem-se adicionar propriedades individuais desejáveis de cada um, tornando-os mais biocompatíveis, com menor possibilidade de falha e com propriedades superiores às dos componentes isolados. Desta forma, o presente trabalho demonstrou uma nova opção de substituto ósseo, biologicamente compatível, ao utilizar um implante ósseo confeccionado a partir de dois biomateriais, sendo um deles biológico (matriz óssea mineralizada heteróloga fragmentada) e o outro sintético (metilmetacrilato), para corrigir falhas ósseas em cirurgias ortopédicas reparadoras.

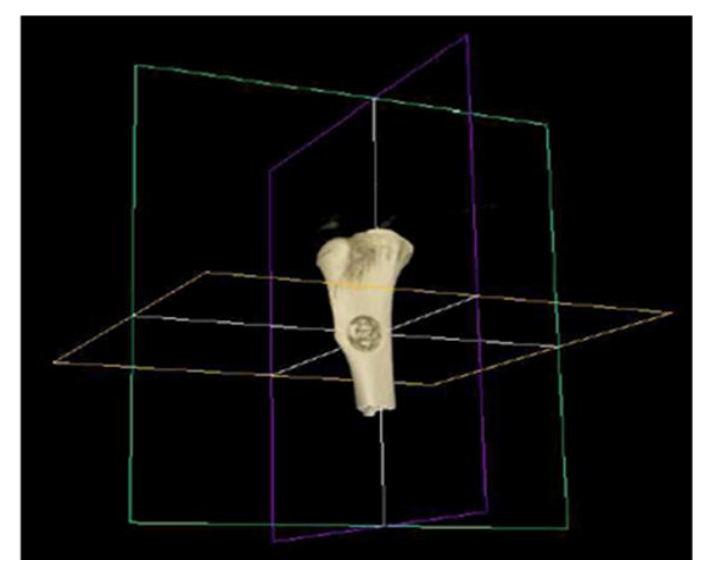

Figura 1. Reconstrução tridimensional (3D) em tomografia computadorizada de feixe cônico (cone beam) no pós-operatório imediato. Notar implante, com áreas radioluscentes e radiopacas, localizado no leito receptor na região metafisária medial da tíbia de coelho. 


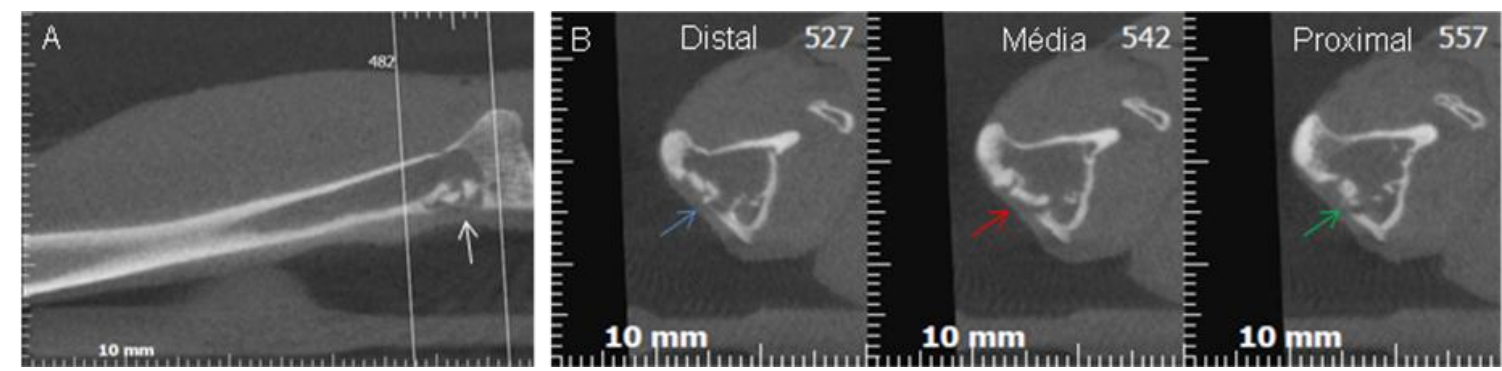

Figura 2. Imagem tomográfica da região proximal da tíbia de coelho aos 30 dias. A: notar implante no leito receptor - seta branca (corte coronal na posição anteroposterior). B: notar ausência de reações nas: porção porções distal - seta azul, média - seta vermelha e proximal - seta verde, do implante no leito receptor (cortes axiais). Cortes: intervalo de $1,1 \mathrm{~mm}$ e espessura de $0,076 \mathrm{~mm}$.
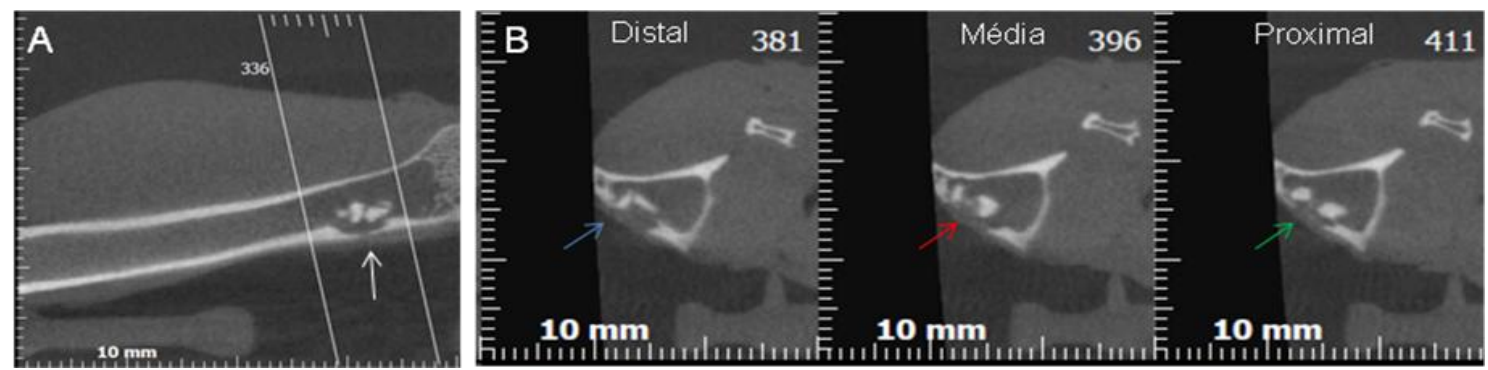

Figura 3. Imagem tomográfica da região proximal da tíbia de coelho aos 60 dias. A: notar implante no leito receptor - seta branca (corte coronal na posição anteroposterior). B: notar ausência de reações que sugere infecção e/ou rejeição nas: porção porções distal - seta azul, média - seta vermelha e proximal seta verde, do implante no leito receptor (cortes axiais). Cortes: intervalo de $1,1 \mathrm{~mm}$ e espessura de $0,076 \mathrm{~mm}$.

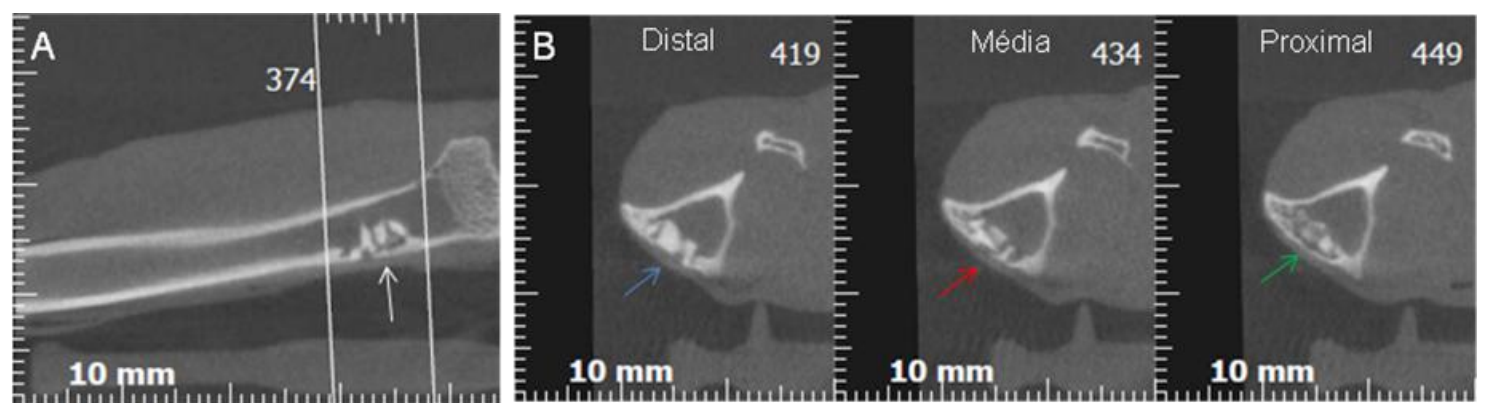

Figura 4. Imagem tomográfica da região proximal da tíbia de coelho aos 90 dias. A: notar implante no leito receptor - seta branca (corte coronal na posição anteroposterior). B: notar ausência de reações que sugere proliferação e/ou rejeição e infecções nas porções distal - seta azul, média - seta vermelha e proximal - seta verde, do implante no leito receptor (cortes axiais). Cortes: intervalo de $1,1 \mathrm{~mm}$ e espessura de $0,076 \mathrm{~mm}$.

\section{CONCLUSÕES}

O uso da matriz óssea mineralizada heteróloga fragmentada associada ao metilmetacrilato promove a reparação de falhas ósseas, sem sinais de infecção, migração e/ou rejeição, caracterizando-se como nova opção de substituto ósseo para preenchimento de falhas ósseas.

\section{AGRADECIMENTOS}

Os autores agradecem o apoio da FAPEMAT (Fundação de Amparo à Pesquisa de Mato Grosso) e UNIFESP (Universidade Federal de São Paulo). 


\section{REFERÊNCIAS}

AKAMOTO, T.; TRENTO, C.L. Implante homógeno de matriz dentinária desmineralizada conservada em glicerina a $98 \%$ em alvéolo dental - estudo microscópico em rato. Rev. Cienc. Odont., n.5, p.33-43, 2002.

ALEXANDER, J.W. Bone grafting. Vet. Clin. N. Am.: Small Anim. Pract., v.17, p.811-819, 1987.

ALIEVI, M.M.; SCHOSSLER, J.E.W.; GUIMARAES, L.D. et al. Implante ósseo cortical alógeno conservado em mel na reconstrução de falha óssea diafisária em fêmur de cães: avaliação clínica e radiográfica. Cienc. Rural, v.37, p.450-457, 2007.

ALVES, E.G.L.; REZENDE, C.M.F.; OLIVEIRA, H.P. et al. Emprego experimental da placa de compósito poli-hidroxibutirado/hidroxiapatita na fixação femoral em gatos. Arq. Bras. Med. Vet. Zootec., v.62, p.1128-1134, 2010.

BAUER, T.W.; MUSCHLER, G.F. Bone graft materials. Clin. Orthop., v.37, p.10-27, 2000.

DE MARVAL, C.A.; ALVES, G.E.S.; LAS CASAS, E.B. De et al. Análise biomecânica ex vivo de um modelo de haste intramedular de polipropileno para osteossíntese em úmeros de bezerros. Arq. Bras. Med. Vet. Zootec., v.63, p.273-278, 2011.

DIPISA, J.A.; SIH, G.S.; BERMAN, A. The temperature problema $t$ the bone-acrylic cement interface of the total hip replacement. Clin. Orthop., v.121, p.95-98, 1976.

FREITAS, S.H.; DÓRIA, R.G.D.; MENDONÇA, F.S. et al. Aspecto radiológico de heteroenxerto ósseo cortical fragmentado na reparação de falhas ósseas em coelhos. Rev. Bras. Cienc. Vet., v.15, p.107-110, 2008.

FREITAS, S.H.; SIMÕES, M.J.; BRINHOLI, R.B. et al. Aplicação de implante ósseo heterólogo pulverizado e conservado em glicerina. Arq. Inst. Biol., v.68, supl., p.158, 2001.

GARIB, D.G.; RAYMUNDO Jr., R.; RAYMUNDO, M.V. et al. Tomografia computadorizada de feixe cônico (Cone beam): entendendo este novo método de diagnóstico por imagem com promissora aplicabilidade na Ortodontia. Rev. Dental Press Ortod. Ortop. Facial, v.12, p.139156, 2007.
GUTIERRES, M.; LOPES, M.A.; HUSSAIN, N.S. et al. Substitutos ósseos: revisão. Arq. Med., v.19, p.153-162, 2006.

IAMAGUTI, P.; INEO, A.P.; DEL CARLO, R.J. et al. Uso de auto-enxerto ósseo esponjoso na reparação do rádio. Estudo experimental em coelhos. Vet. Zootec., v.7, p.49-61, 1995.

MELO, E.G.; REZENDE, C.M.F.; BORGES, A.P.B. et al. Aloenxerto ósseo cortical: avaliação do seu emprego em tíbia de cão. Arq. Bras. Med. Vet. Zootec., v.50, p.385-394, 1998.

MORAIS, P.C.; PADILHA FILHO, J.G.; CANOLA, J.C. et al. Biocompatibilidade do cimento de fosfato de cálcio implantado no rádio de coelhos. Acta Cir. Bras., v.19, p.351-359, 2004.

MURILLO, C.H.; OCHOA, F.A.; ORTEGÓN, P.S.M. et al. Análisis radiográfco convencional y digital computarizado en evaluación ósea para la colocación de implantes. Uni. Odontol., v.19, p.9-13, 1999.

PIERMATTEI, D.L.; GREELEY, R.G. Atlas de abordagens cirúrgicas aos ossos do cão e do gato. 2.ed. São Paulo: Manole, 1988. 197p.

RANZANI, J.J.T.; SAMPAIO, G.R.; FRANCO, M. et al. Aplicação de membrana biológica heteróloga conservada em glicerina, na reparação de lesão em coelhos. Vet. Zootec., v.8, p.35-45, 1996.

RAPOSO-do-AMARAL, C.A.A.; RAPOSO-doAMARAL, C.E.; ROLAND, F.G. et al. Implantes pré-fabricados customizados nas grandes perdas ósseas do esqueleto craniofacial. Rev. Bras. Cir. Craniomaxilof., v.3, p.175-179, 2010.

REZENDE, C.M.F.; BORGES, A.P.B.; BERNIS, W.O. et al. Aspecto clínico-cirúrgico e radiográficos da hidroxiapatita sintética na diáfise proximal da tíbia de cães. Arq. Bras. Med. Vet. Zootec., v.50, p.537-545, 1998.

SILVA, A.M.; DEL CARLO, R.J.; VILORIA, M.I.V. et al. Matriz óssea homóloga desmineralizada na preparação de falhas ósseas segmentares produzidas no rádio de coelhos. Cienc. Rural, v.33, p.539-545, 2003. 
SILVEIRA, A.C.G.; WASSALL, T. Análise da área doadora de enxerto mandibular por meio de tomografia computadorizada do feixe cônico para avaliação da remodelação óssea. Rev. Gaúcha Odont., v.57, p.61-65, 2009.

SPADETO Jr., O.; RODRIGUES, L.B.; CARVALHO, W.T.V. et al. Sistemas ossoimplante ex vivo utilizando haste intramedular polimérica para imobilizaçãode fraturas femorais em bovinos jovens. Cienc. Rural, v.41, p.301-06, 2011.

SUOMINEN, E.A.; AHO, A.J.; JUHANOJA, J. et al. Hydroxyapatiteglass composite as a boné substitute in large metaphyseal cavities in rabbits. Inter. Orthop., v.19, p.167-173, 1995.
TURRER, C.L.; FERREIRA, F.P.M. Biomateriais em cirurgia craniomaxilofacial: princípios básicas e aplicações: revisão de literatura. Rev. Bras. Cir. Plast., v.23, p.234-239, 2008.

VILELA, L.M.; DEL CARLO, R.J.; OLIVEIRA, R.C. et al. Propriedades mecânicas de meniscos frescos de coelhos e preservados em glicerina 98\%. Cienc. Rural, v.40, p.1114-1120, 2010.

WEINFELD, I.; MAGALHÃES, L.V.; VILA, N. Estudo histológico de um novo material (biobone) indicado para reparação óssea. Rev. Paul. Odont., v.21, p.9-10, 1999.

YACUBIAN-FERNANDES, A.; LARONGA, P.R.; COELHO, R.A. et al. Prototipagem como forma alternativa para realização de cranioplastia com metilmetacrilato: nota técnica. Arq. NeuropPsiquiatr., v.62, p.865-868, 2004. 